University of Windsor

Scholarship at UWindsor

OSSA Conference Archive

May 18th, 9:00 AM - May 21st, 5:00 PM

Semantic penumbra? Concept similarity in logic

John Woods

University of British Columbia, King's College, London

Nicholas Griffin

Follow this and additional works at: https://scholar.uwindsor.ca/ossaarchive

Part of the Philosophy Commons

Woods, John and Griffin, Nicholas, "Semantic penumbra? Concept similarity in logic" (2011). OSSA Conference Archive. 61.

https://scholar.uwindsor.ca/ossaarchive/OSSA9/papersandcommentaries/61

This Paper is brought to you for free and open access by the Conferences and Conference Proceedings at Scholarship at UWindsor. It has been accepted for inclusion in OSSA Conference Archive by an authorized conference organizer of Scholarship at UWindsor. For more information, please contact scholarship@uwindsor.ca. 


\title{
Semantic penumbra? Concept similarity in logic
}

\section{JOHN WOODS}

\author{
University of British Columbia \\ and \\ King's College, London \\ john.woods@ubc.ca
}

\begin{abstract}
It is widely accepted by formal and informal logicians alike that a formal logic which, by the lights of English, gets the connectives wrong, nevertheless conspires to get entailment right - right that is, modulo English. There is a vexing problem occasioned by this semantic alienation of formal logic. It is next to impossible for formal logic to meet the expectations of realism. What, then, of informal logic?
\end{abstract}

\section{CONCEPT SIMILARITY}

Informal logicians exhibit an interesting ambivalence towards deduction and its logic. They acknowledge that deductive validity is a good property for an argument or piece of reasoning to have. There is also an equable consensus about what that property is. Sometimes the affection for validity runs to favouritism. Many an informal logician thinks that validity is the best of the good-making ties between an argument's premisses and its conclusion. ${ }^{1}$ Informal logicians have a corresponding fondness for the logic of deduction. There is wide agreement that formal deductive logic produces a satisfactory, indeed exemplary, account of the property of validity or equivalently, of the relation of logical entailment.

Despite this amity with the deductive, another distinctive feature of the informal logic movement has been its dissatisfaction with formal logic. In saying so, a certain caution is necessary. When informal logicians lay the charge of inadequacy against deductive logic, they are finding fault with it notwithstanding their belief that it gives the right account of that subject's most central target concept. Where, then, is the trouble to be found? It is to be found in the schematization manual that takes sentences from subsets of English to well-formed formulas (wffs) of the formal calculus of the logic. A particular part of this worry - though not by any means the whole of it ${ }^{2}$ - has to do with the entirely correct observation that the connectives of deductive logic distort the meanings of their English counterparts.

This is embarrassing. At least, it is embarrassing on its face. The connectives of formal deductive logic are included in its logical particles. The system is designed in such a way that the logical particles play a semantically indispensable role in specifying the entailment relation. But now we must ask, "How is this possible?" How is it possible to get entailment right if the very same system gets entailment's logical particles wrong?

1 Inductive strength comes second in such rankings, with connections of lesser robustness bringing up the rear-abductive implication, conductive implication, defeasible implication, and on and on.

2 It is a big and tricky problem, too much to be dealt with here. Interested readers may wish to consult Woods (2004: chapter 3).

Zenker, F. (ed.). Argumentation: Cognition and Community. Proceedings on the $9^{\text {th }}$ International Conference of the Ontario Society for the Study of Argumentation (OSSA), May 18-21, 2011. Windsor, ON (CD ROM), pp. 1-10. 
How does one get anything right by getting something else wrong? This is an issue important enough to have a name. I propose that we call it the Right-Wrong Problem.

There is, of course, an intuitive answer (of sorts) to the Right-Wrong Problem. It is that while logic gets the logical particles wrong, there is nevertheless enough similarity between how they actually are and how they are represented by logicians to defeat the supposition that the Right-Wrong asymmetry is a genuine problem. This is not a silly idea. But before we take to it with theoretical seriousness, we should specify this relation of purported similarity and demonstrate its key properties. As a first attempt, I shall call upon the concept of semantic penumbra, to be introduced just below.

Virtually everyone agrees that it is at least a necessary condition of the entailment of $\psi$ by $\Phi$ that it not be possible that $\Phi$ and not- $\psi$. With a nod to its lineage in logics of strict implication, let's call this the strict condition on entailment. Classical and modal logicians see the strict condition as also sufficient for entailment. So far as I can tell, so do most informal logicians. Relevant and paraconsistent logicians plump for its necessity only. There is no urgency to adjudicate this conflict here. Suffice it to say that virtually everyone agrees that in advancing the strict condition, a logic takes a considerable stride in getting the entailment relation right.

\section{SEMANTIC PENUMBRA}

To see how Right-Wrong arises, it would be useful to consider classical first order logic (CFL). For present purposes we might just as well have chosen a modal system such as S5. I will have occasion to mention S5 later in the talk. But everyone is familiar with CFL. So we're starting with it. Everyone also agrees on CFL's principal target. CFL's job is to provide clear and rigorous definitions of a family of interlocking notions centering around the relation of logical entailment, to demonstrate the key properties of these notions and, to the degree possible, facilitate their recognition. A significant factor in performing these tasks is that CFL's target properties are defined for syntactic constructions from the system's formal language. Key to it all is the semantic interpretation the system attaches to its logical particles: $\sim, \wedge, \vee, \supset, \equiv, \exists$, for each of which in turn there is a purported counterpart in English: "not", "and", "or", "if ... then", "if and only if" and "some". If getting entailment (etc.) right is CFL's principal target, dealing with negation, conjunction, disjunction, conditionality, biconditionality and existential quantification is CFL's subsidiary target. ${ }^{3}$

No one seriously supposes that the connectives and their respective counterparts mean the same. There is no sense of "if ... then" in English for which $\Phi$ 's falsity verifies IIf $\Phi$ then $\psi\urcorner$ for arbitrary $\psi$, and for which $\psi$ 's truth verifies that same conditional. That is there is no sense of "if ... then" in English in which $\ulcorner\Phi \supset \psi\urcorner$ says $\ulcorner$ If $\Phi$ then $\psi\urcorner$.

Even CFL's negation doesn't quite fit negation in English. Russell noted long ago that there is a use of "not" in English in which "Not- $\Phi$ ' can be true even though $\Phi$ is not false. ( $\Phi$ might be "The present king of France is bald" (Russell 1905)).

This is not to say that the sentential operators aren't interesting. Jennings (1994) is very good book on disjunction and Horn (1989) is the same for negation. The point is that the job of a theory of deduction is to get deduction right. It is not the job of a theory of deduction to pronounce upon negation save in ways that may facilitate its progress with deduction (which in its semantic sense is what entailment is). 
We have it, then, that CFL gets the English particles wrong - not dead wrong perhaps, but wrong enough to notice. Yet there is a substantial consensus that it gets entailment right. ${ }^{4}$ But why would this be so? How could a logic that gets "if ... then" wrong turn out to get "is a consequence of" right? (Whereupon the Right-Wrong Problem.)

The answer that I will now consider is that the CFL-connectives are in the "semantic penumbra" of their counterpart expressions in English. Consider first the case in which the semantic gap between a CFL connective and its counterpart in English is starkest: "つ" and "if ... then". Notwithstanding their difference, they exhibit a similarity:

- The truth of $\ulcorner\sim(\Phi \wedge \sim \psi)\urcorner$ is necessary and sufficient for the truth of $\ulcorner\Phi \supset \psi\urcorner$, and is necessary though not sufficient for the truth of $\ulcorner$ If $\Phi$ then $\psi\urcorner$.

Accordingly, we may say that, while " $\supset$ " and "if ... then" don't mean the same, "つ" is in the semantic penumbrum of "if ... then".

Consider next the less dissonant case of negation.

- The falsity of $\Phi$ is necessary and sufficient for the truth of $\ulcorner\sim \Phi\urcorner$, and is sufficient but not necessary for the truth of $\ulcorner$ Not $-\Phi\urcorner$.

Accordingly, while " $\sim$ " and "not" don't mean the same, " $\sim$ " is in the semantic penumbrum of "not".

The cases generalize: Let $\mathrm{K}^{\mathrm{F}}$ be a logical particle of a logical system and $\mathrm{K}^{\mathrm{E}}$ its counterpart in English. Then $\mathrm{K}^{\mathrm{F}}$ is in the semantic penumbrum of $\mathrm{K}^{\mathrm{E}}$ just in case either

(1) there is a condition necessary and sufficient for the truth of a $\mathrm{K}^{\mathrm{F}}$-statement that is sufficient but not necessary for the truth of the counterpart $\mathrm{K}^{\mathrm{E}}$-statement; or

(2) there is a condition necessary and sufficient for the truth of a $\mathrm{K}^{\mathrm{F}}$-statement which is necessary but not sufficient for the truth of the counterpart $\mathrm{K}^{\mathrm{E}}$-statement.

In my dictionary, one of the listings for "penumbrum" is any area of partial shade. Something of that meaning is preserved here, with formal terms occupying the lighter areas in the partial semantic shade of their English counterparts.

Semantic penumbra reflect an interesting suggestion about getting things right. We've already noticed that, speaking loosely, getting the particles right seems not to be a condition on CFL's getting entailment right. If we wanted to say this more accurately, we could propose that what our examples show is that if you want to get entailment right, it is not necessary to get your logical particles as right. It suffices that you get them right enough.

Semantic penumbra offer a test of this enoughness. You've handled your logical particles well enough if they are in the semantic penumbra of their respective counterparts in English. Let us call this the semantic penumbrum thesis. ${ }^{5}$ Could the semantic penumbrum thesis be the answer we want for the Right-Wrong Problem?

4 In CFL $\Phi$ entails $\psi$ just in case there is no valuation making $\Phi$ true on any interpretation that doesn't also make $\psi$ true on that interpretation. More loosely, there is no possible way of making $\Phi$ true without making $\psi$ true. This, of course, is the strict condition.

5 Of course, CFL doesn’t need “つ”. It can get by perfectly well with “ $\sim$ ” and “ $\wedge$ ”, concerning which all agree that the fit with their respective English counterparts is a good deal more intuitive. Similarly, CFL 
Over the years, informal logicians have been much exercised by CFL's failure to get the connectives right. ${ }^{6}$ This, they say, is a misrepresentation problem. So it is. There is a good deal of inclination to regard this misrepresentation as a bad problem. If the semantic penumbrum thesis were true, these critics would be right in the first instance and wrong in the second. That is, CFL does misrepresent the connectives, but the damage is merely local - that is, it compromises the system's subsidiary ambitions without laying a glove on its principal ambition.

Suppose this is so. Suppose that the semantic penumbrum thesis offers a satisfactory resolution of the Right-Wrong problem. Wouldn't this mean that informal logicians should revise their position on the misrepresentations occasioned by deductive logic's logical particles? Shouldn't they now concede that while those misrepresentations do indeed exist they are no longer grounds for complaint? This is a point to which I'll return.

\section{LOSING NEGATION}

The semantic penumbrum thesis is not without its problems. Here is one of them. Negation, we might say, begins at home. But consider now negation of a rather distant stripe. One of the mainstream approaches to relevant logic is called first order entailment (FDE). One of the main approaches to FDE's semantics is the so-called Routley-star semantics. Here, briefly, are the technicalities. In Routley's possible worlds semantics for FDE, every world $w$ has a unique buddy $w^{*}$, called its star world. An interpretation of FDE is a structure $\langle\mathrm{W}, *, \mathrm{v}\rangle$ in which $\mathrm{W}$ is a set of worlds, * is a function from worlds to worlds satisfying the condition that $w^{* *}=w$, and $\mathrm{v}$ is a truth value assignment. Negation is now defined as: $\mathrm{v}_{w}(\sim \Phi)=\mathrm{T}$ if and only if $\mathrm{v}_{w^{*}}(\Phi)=\mathrm{F}$. That is, it is necessary and sufficient for the truth in this world of $\sim \sim \Phi\urcorner$ that $\Phi$ be false in its star world. Call this the star condition.

It is widely held that FDE gets logical consequence just about right. Since FDE is a relevant logic, it accepts the strict condition as necessary but not sufficient for entailment. One of its most interesting features is that its notion of negation answers to nothing that qualifies as negation in any sense of "not" in English. This is acknowledged by its inventors and supporters. ${ }^{7}$ FDE's "negation" is negation in no discernible sense. ${ }^{8}$

doesn't need " $\exists$ ". It can make do with " $\forall$ ", whose fit with the "all" of English is hardly in doubt. Yes, this is so. But it doesn't matter. It doesn't matter because there is no sense of "if ... then" in English for which $\ulcorner\sim(\Phi \wedge \sim \psi)\urcorner$ says $\ulcorner$ If $\Phi$ then $\psi\urcorner$. Accordingly, there is no English sentence $\ulcorner$ If $\Phi$ then $\psi\urcorner$ not misrepresented by $\sim(\Phi \wedge \sim \psi)\urcorner$. Yet it remains true that CFL gets entailment right.

6 Not only informal logicians: One of the more instructive early disputes about the tenability of "つ" pits Hugh MacColl against Russell. See, for example, MacColl (1905, 1908a, 1908b). There also exists a substantial correspondence between MacColl and Russell, cited in Rahman and Redmond (2008). Here is some wise instruction from MacColl: "Thus, Mr. Russell, arguing correctly from the customary convention of logicians, arrives at the strange conclusion that (among Englishmen) we may conclude from a man's red hair that he is doctor, or from his being a doctor that (whatever appearances may say to the contrary) his hair is red" (MacColl 1908a, p. 152). For further dissatisfactions with how CFL handles its logical particles, see Adams (1988), Stove (1986), McGee (1985) and Jacquette (1999). These are discussed in Woods (2004: chapter 3).

7 See, in addition to Routley and Routley (1972), Priest (2008). Restall (1999) is an exception. Restall has learned to love star negation.

8 Thus calling to mind Quine's words about a different though related thing. Speaking of the dialetheic approach to entailment, Quine writes: "To turn to a popular extravaganza, what if someone were to re- 
FDE gets negation dead wrong. Yet it gets entailment dead right, or some near thing. So it can't be a blanket condition on getting entailment right that we get our connectives even somewhat right.

Why would we think that FDE gets entailment dead right or some near thing? We would think it because FDE imposes the strict condition on entailment: $\Phi$ entails $\psi$ only if it is not possible that $\Phi \wedge \sim \psi$. Yes it does. That is, FDE imposes a condition formulable in those words. But how can the following three things be true: that " $\sim$ " means nothing recognizable as negation, that " $\sim$ " occurs essentially in the wording of the strict condition, and that the ensuing meaning of "entails" is close enough to its meaning in English to warrant our saying that this very wording gives the strict condition for that very sense of entailment - that is, its sense in English?

It's not a sellable proposition. If the definiens of a definiendum invokes no recognizable concept, the definiendum itself imbibes that limitation. FDE's star negation is one in which negation is unrecognizable. Equally, FDE's entailment is one in which entailment is unrecognizable. So there is no Right-Wrong Problem for FDE. FDE is wrong through and through.

We might see in this a critical difference with CFL. If we continue to think that CFL gets entailment more right than it gets the English connectives, the Right-Wrong Problem remains in effect. As before, it is a problem in need of a solution. If the semantic penumbrum thesis were the right way to go, the thesis would hold for CFL and fail for FDE. It would fail for FDE if star-negation weren't in the semantic penumbrum of negation in English. This has a promising look. For how could star-negation be in the semantic penumbrum of negation in English given that there is in star negation nothing recognizable as negation?

A logical connective is in the semantic penumbrum of its English counterpart just in case a defining condition of the former is a necessary only or a sufficient only part of the definition of the latter. In the case of star negation, we see that $\left.{ }^{\sim} \sim \Phi\right\urcorner$ is true in this world just in case $\Phi$ is false in its star world. Informally, $\sim \Phi\urcorner$ is true if and only if $\Phi$ is not actually but only possibly false. Of course, $\Phi$ 's possible falsity is a necessary condition on its actual falsity. But since $\Phi$ 's actual falsity is neither necessary nor sufficient for the truth of the star-statement $\left.{ }^{\sim} \sim \Phi\right\urcorner$, the condition that is necessary and sufficient for the truth of $\ulcorner\sim \Phi\urcorner$ is neither necessary only or sufficient only for the truth of ${ }^{\ulcorner}$Not- $\left.\Phi\right\urcorner$ in English. So star negation is not in the semantic penumbrum of real negation; and this at least suggests an exploitable connection between a concept's not being recognizable in a piece of notation and the failure of that notation to be in the semantic penumbrum of the English notation in which the concept is fully recognizable. This is a telling concurrence. CFL's " $\sim$ " works like the "not" of English, sufficiently so that CFL poses a Right-Wrong Problem, where FDE trivially does not. (We might say that it poses a Wrong-Wrong Problem.)

There is something satisfying about this and something else that is not. The satisfying part is the encouragement to retain semantic penumbrumancy as the explanation of what makes the operations of CFL recognizable, what makes them negation-like, con-

ject the law of non-contradiction and so accept an occasional sentence and its negation both as true? ... My view ... is that neither party knows what he is talking about. They think that they are talking about negation, ' $\sim$ ', 'not'; but surely the notation ceased to be recognizable as negation when they took to regarding some conjunctions of the form ' $p . \sim p$ ' as true, and stopped regarding such sentences as implying all others" (Quine 1982: 81). 
junction-like, conditionality-like, and so on. The unsatisfying part is our decision to retain the Right-Wrong Problem for CFL. Doing so would be a mistake, as the FDE case makes clear. Here is why.

In its most circumspect formulation, the Right-Wrong thesis is that CFL gets the entailment relation pretty close to right, certainly more so than it gets its connectives right. We had no difficulty in seeing that the unrecognizability of negation in FDE's " $\sim$ made for the unrecognizability of entailment in FDE's term for it. The same applies here, only less dramatically. That the English operations are only somewhat recognizable in CFL's connectives makes entailment equally recognizable in CFL's "entails", namely somewhat only. CFL does no better as an analysis of entailment than it does an analysis of the operations to which the English connectives correspond. It is a truth of English that $\Phi$ entails $\psi$ only if it is necessarily the case that if $\Phi$ then $\psi$. In CFL, this is likened to 'Necessarily, $\Phi \supset \psi\urcorner$. But there is no sense of "if ... then" in English for which $\left.{ }^{\ulcorner} \Phi \supset \psi\right\urcorner$ conveys that if $\Phi$ then $\psi$. So, as regards entailment, the gap between English and CFL is no laughing matter. It provides that CFL gets entailment wrong. Not dead wrong, but wrong enough to notice.

In what we've been saying so far, CFL has been a stand-in for one's favourite formal logic of entailment. Some may think, as Lewis himself did (and MacColl before him), that modal logic is a better instrument for that purpose, made so by the fact that, not only does it impose the strict condition on entailment, but it also says what the strict condition means. Both logics call upon possibility in their definitions of entailment. But wouldn't a logic that tells us how possibility actually goes give us a richer grasp of entailment? Wouldn't a logic that tells us what possibility means give us a deeper appreciation of entailment? Yes it would. At least, it would to the extent to which possibility is recognizable in the logic's symbol for it, " $\diamond$ ". In some modal systems, possibility is not recognizable in " $\diamond$ ". In others " $\diamond$ "is more possibility-like. (Think of S2 in the first instance and of S5 in the second.) The possibility-likeness question turns out to be harder than it might have appeared to be. ${ }^{9}$

\section{CONCEPTUAL INDIVIDUATION}

The present suggestion, that the sense of "entails" captured by those modal systems of logic that come closest to the meaning of "entails" in English, still leaves a non-trivial gap between them. Let S5 stand in for them all. There is a body of opinion - but not a shred of even informal proof - that the necessities of S5 are valid statements, which in turn are statements true solely in virtue of their logic forms. ${ }^{10}$ Accordingly, the entailments of S5 would be given by sentences $\ulcorner$ Necessarily $(\Phi \supset \psi)\urcorner$ —and, equivalently, $\sim$ Possibly $(\Phi \wedge$ $\sim \psi)\urcorner$ - made true solely by their logical forms. The present suggestion also carries the assumption that the meaning that S5 assigns to "entails" incorporates the clause "in virtue of logical form". If this is so, if the meaning of "entails" is such that no sentence made true by

9 The trouble is that it is not at all easy to see whether there actually are senses of "possible" in English which are recognizable in any of the varying provisions the large family of modal logics makes for " $\diamond$ ". So far "nothing constitutes even an informal "proof" that these recognizabilities exist. See Burgess (2009: 65).

10 On this same view, the necessities of $\mathrm{S} 4$ are demonstrabilities - that is, sentences provable by virtue of logical form alone. 
considerations other than-or independently of - logical form is an entailment in the S5 sense, then there are large classes of entailments in English that aren't true in the S5 sense. Consider here entailments flowing from genus-species relations ("The figure is square" entails "The figure is rectangular") and from determinate-determinable connections ("The shirt is red" entails "The shirt is coloured"). Informal logicians have a large stake in understanding informal entailments of these sorts. But these examples have no standing in S5. So, again, why this deference to S5 (and the others, as may be)?

"Yes, of course. But the fact remains, doesn't it, that S5's concept is indeed like the one in English, and like enough to make it possible for people interested in the informal entailments of English to learn something about them by attending to what entailments are like in S5?' It is an interesting suggestion, well worth some sympathetic attention. If it were true, the following might also be true. It might be that there is a concept of entailment which is instantiated by formal sentences in the ways chronicled by S5, and which is also instantiated in English by, among others, those entailments to which genusspecies and determinate-determinable relations give rise. Thus it would be the same concept differently instantiated - that is, with different extensions - in S5 and English. What is more, there would be a critical respect in which S5 would have beaten informal logic to the punch. S5 would have told us what this shared concept actually is. It would have told us what "entails" in S5 means, and in so doing it also would have told us what "entails" means in English. S5 has proved loads of theorems about entailment, hence loads of theorems about entailment in English.

What is wanted now is a credible, similarity claim with respect to CFL's entailment in relation to the entailment of English. We want the same for that veritable plethora of different and often incompatible formalizations of that same relation-for K, S4, S5 and so on. Consider now the strict condition on any reading of it in which " $\sim$ " is recognizable as negation, " $\sim$ " as conjunction and "possibly" as possibility; thus satisfying the semantic penumbrum condition in each instance. Let $\mathcal{F}$ be the family of distinct sets of entailments generated by fulfillment of the strict condition on each such different reading of it. Supposing that there is a generic relation of entailment, we might suppose that each member of $\mathcal{F}$ is a distinct species of that generic relation. What is more, since on each reading entailment is defined via negation, conjunction and possibility, these readings too define species of the generic operations of negation, conjunction and possibility. Here, too, particle similarity would be specieshood of a common genus.

One of the attractions of the genus-species approach to the logic of entailment is that it permits recognition of logic's sprawling pluralism without the necessity of a nihilistic relativism in which there is no fact of the matter about entailment except relative to the system that defines it. Here is why.

Consider a different case. There are different and incompatible ways of being a species of mammal - think of whales and us for example. But there is only one way of being a mammal. Suppose, as regards some species, there were a good theory $\mathcal{T}$ of what it took for any member of it to be a mammal. Then $\mathcal{T}$ would be a good theory of what it took for any mammalian of any species to be a mammal. This would be so even if the intersection of all the species were empty. If the genus-species parallel held for entailment, then the CFL, K, S4 and S5 entailments would all resemble generic entailment in ways that constitute them as species of it. CFL would be a good theory of the generic relation of entailment notwithstanding that its sentences constitute a distinct species of it. 
Each specific relation would be sufficiently similar to the generic relation to make each of them recognizable as entailment.

This would be interesting news if true. It would vindicate an informal logician's deference to formal logic in matters pertaining to argument-validity, consistency and the like. It would allow us to reconsider the Right-Wrong Problem. If, for example, entailment ${ }^{\mathrm{S} 5}$ were the same concept as entailment ${ }^{\mathrm{E}}$ then we would have it that the semantic gap between the connectives of S5 and English doesn't carry over to their respective concepts of entailment. Hence the Question is revived (but not answered).

There would be further benefits. Here is one of them. With the exception of autoepistemic logics, all of computer science's defeasibility logics arise from classical logic by attaching to classical entailment various and shifting families of conditions. ${ }^{11}$ In all these systems connectives are interpreted classically. ${ }^{12}$ Let $\mathcal{D}$ be the class of these defeasibility logics. Every member of $\mathcal{D}$ represents its consequence relation as obtaining solely in virtue of logical form. In recent years, informal logicians have been much preoccupied with defeasible reasoning in English. For the most part, their investigations proceed without engagement of anything that goes on in $\mathcal{D}$. In rare exceptions, items in $\mathcal{D}$ is mentioned, but without any consideration of the possibility that the concepts of defeasible consequence in $\mathcal{D}$ are different from the concepts instantiated by defeasible reasoning in English. Whereupon our earlier question recurs. Is any of the $\mathcal{D}$-concepts of defeasible consequence the same as any concept of defeasible consequence instantiated by defeasible reasoning in English? Or are they all different?

Once again, it would be interesting if it turned out that for any concept of defeasible consequence instantiated in English there is a $\mathcal{D}$-concept with which it is identical. For here, too, we could say that $\mathcal{D}$-logicians had got a step on informal logicians. We would say that $\mathcal{D}$-logicians had actually got around to saying what "defeasibly entails" means and, in those cases in which the concept is instantiated in English, they would also have managed to say what "defeasibly entails" means in English.

The key to it all is concept-identity. When concept $\mathrm{C}$ and concept $\mathrm{C}^{*}$ are the same concept, there are conditions in virtue of which this is so. Following Quine, let's call these conditions the identity conditions for the concepts in question. Quine is famous for saying that an acquaintance with a thing's identity conditions enables us to know where it ends and another thing of like kind begins. Quine is even more famous for thinking that in the absence of identity conditions we can't know what we're talking about. I myself demur from this grim sort of epistemological Puritanism. But I readily agree that it sometimes matters to claims one makes or entertains about given concepts whether they are indeed the same concept. In such cases identity conditions are fair game; for they are invited not imposed.

11 Autoepistemic logics are made so by the addition to its classical connectives of the so-called introspective modal operator. Two other exceptions are the theory of defeasible inheritance sets and the abstract theory of argument defect. In these cases, the role of logical connectives is much diminished. A third exception, on its fact at least, are systems of logic programming with negation-as failure. But David Makinson claims, and I agree with him, that there are ways to "reclassify" these rules (Makinson 2005: chapter 4).

12 So it would be as wrong to think of defeasibility logics as rivals of classical logics, as it would be wrong to think of S5 as a rival of CFL. 
So let us ask: Are there identity conditions for what concerns us here? Do we have a principled means of determining whether S5's concept of entailment is the same as the English concept, and whether there is a concept of $\mathcal{D}$-entailment which is the same as the defeasible concept instantiated in English? At this writing, the concept-identity project has achieved no foothold in logic, informal or otherwise. ${ }^{13}$ This matters for informal logic and for formal logic alike. It matters because informal logic has not produced a semantics for entailment and defeasible entailment, and formal logic has. If the formal concepts are the same as the informal ones, there is no definitional loss for informal logic to make up. When it comes to the exposure of meaning, formal logic will already have done that work. It will have done that work provided the respective concepts are the same. On the other hand, if concept-identity theory leaves the identity of entailment ${ }^{\mathrm{E}}$ and entailment ${ }^{\mathrm{S} 5}$ unpronounced upon, the possibility that they are not the same cannot be shirked, and, with it, the possibility that on the score of validity informal logic's deference to formal logic is more hopeful than justified.

At present we don't know whether the formal and English concepts of entailment are the same. We should try to find out. There is a challenging and necessary research programme which informal logicians should take up. It bids the logician to achieve some acquaintance with the concept-identity project in philosophy. There is work to do and careers to be made.

There is another thing informal logicians might consider worthwhile. It is to bring themselves up to date on the state of play in formal theories of that burgeoning class of consequence relations mentioned just above. For-supposing that the conceptidentity thesis were true- how else are they going to find out what "entails" means in English, in whatever semantic variations as may be present there?

13 The concept project is starting to gear up in philosophy. State of the art information is liberally available in Margolis and Laurence (1999). 


\section{JOHN WOODS}

\section{REFERENCES}

Adams, E. (1988). Modus Tollens revisited. Analysis 48, 122-128.

Burgess, J.P. (2009). Philosophical Logic. Princeton: Princeton University Press.

Horn, L.R. (1989). A Natural History of Negation. Chicago: The University of Chicago Press.

Jacquette, D. (1989). Logic Methodology and Philosophy of Science Abstracts.

Jennings, R.E. (1994). The Genealogy of Disjunction. New York: Oxford University Press.

MacColl, H. (1905). The existential import of propositions. Mind 14, 401-405.

MacColl, H. (1908). 'If' and 'imply'. Mind 17, 151-152.

MacColl, H. (1908). 'If' and 'imply'. Mind 17, 453-455.

McGee, V. (1985). A counterexample of modus ponens. Journal of Philosophy 82, 462-471.

Makinson, D. (1999). Bridges From Classical to Nonmonotonical Logic, London: College Publications.

Margolis, E., and Laurence, S. (eds) (1999). Concept: Core Readings. Cambridge, MA: MIT Press.

Priest, G. (2008, $\left.{ }^{1} 2001\right)$. An Introduction to Non-Classical Logic: From If to Is. New York: Cambridge University Press.

Quine, W.V. (1982). Philosophy of Logic, $2^{\text {nd }}$ edition. Cambridge, MA: Harvard University Press.

Rahman, S., and Redmond, J. (2008). "Hugh MacColl and the birth of logical pluralism." In: Gabbay, D.M., and Woods, J. (eds). Handbook of the History of Logic, Vol 4: British Logic in the Nineteenth Century (pp. 533-604). Amsterdam: North-Holland.

Restall, G. (1999). Negation in relevant logics (how I stopped worrying and learned to love the Routley star). In: Gabbay, D.M., and Wansing, H. (eds). What is Negation? (pp. 53-76). Dordrecht and Boston: Kluwer.

Routley, R., and Routley, V. (1972). The semantics of first degree entailment. Noûs 6, 335-375.

Russell, B. (1905). On denoting. Mind 56, 479-493.

Stove, D. (1986). The Rationality of Induction. Oxford: Clarendon Press.

Woods, J. (2004). The Death of Argument: Fallacies in Agent-Based Reasoning. Dordrecht, Boston: Kluwer. 


\title{
Shining light in dark places. Commentary on "SEMANTIC PENUMBRA" by John Woods
}

\section{NICHOLAS GRIFFIN}

\author{
Department of Philosophy \\ McMaster University \\ Hamilton, Ontario \\ Canada \\ ngriffin@mcmaster.ca
}

\section{INTRODUCTION}

As not uncommonly happens with John Woods' papers, he tackles such difficult problems with such a wealth of ideas that one might spend the whole conference trying to get to grips with them. Faced with such a circumstance what is a poor commentator to do in ten minutes? Well, the short answer to that is that I'm going to make a criticism, a reply (or at least the beginnings of one), an endorsement and a proposal. My comments will, in dire necessity, be brief.

\section{A CRITICISM}

Though the term "semantic prenumbrum" is Woods', the idea behind it, that the logical particles of English cast semantic shadows within which the logical particles of formal languages may (or may not) fall, has appealed to a number of philosophers, especially logicians touting their connectives (and especially if those connectives are new and unusual). Woods admirably attempts to make this notion precise by means of his two-part penumbrum condition, viz.:

If $\mathrm{K}^{\mathrm{F}}$ is a logical particle of a logical system and $\mathrm{K}^{\mathrm{E}}$ its counterpart in English, then $\mathrm{K}^{\mathrm{F}}$ is in the semantic penumbrum of $\mathrm{K}^{\mathrm{E}}$ just in case either:

(1) there is a condition necessary and sufficient for the truth of a $\mathrm{K}^{\mathrm{F}}$-statement that is sufficient but not necessary for the truth of the counterpart $\mathrm{K}^{\mathrm{E}}$-statement;

or

(2) there is a condition necessary and sufficient for the truth of a $\mathrm{K}^{\mathrm{F}}$-statement which is necessary but not sufficient for the truth of the counterpart $\mathrm{K}^{\mathrm{E}}$-statement.

This is a brave attempt, though it has its problems. The condition as stated will place classical, truth-functional disjunction in the penumbrum of the English conjunction, and classical truth-functional conjunction in the penumbrum of the English disjunction. In the first case: it is a necessary but not a sufficient condition for the truth of an English conjunction that at least one of its conjuncts be true, while it is a necessary and a sufficient condition for the truth of " $p \vee q$ " that at least one of its disjuncts be true. In the second case, it is a sufficient, but not a necessary, condition for the truth of an English disjunc- 
tion (at least some of them) that both of its disjuncts be true, while it is a sufficient and a necessary condition for the truth of " $p \wedge q$ " that both its conjuncts be true.

But, although I can't endorse Woods's version of the penumbrum condition, I cannot praise too highly his attempt to state such a condition precisely. The notion of a semantic penumbrum has been appealed to repeatedly, but very little has been done to explicate the notion precisely, carefully, and in full generality. I don't despair that some less elegant condition may work. ${ }^{1}$

\section{A REPLY}

The point on which I want to reply concerns negation, perhaps of all connectives the one with the murkiest penumbrum (or perhaps, indeed, penumbra). Though sometimes hailed as the simplest of logical notions, it is nonetheless the one which lies at the heart of many deep philosophical issues. What part of 'not' don't we understand? Pretty much all of it, in my view.

Here I want to defend relevant negation, the type of formal negation used in Routley and Routley's system of first degree entailment as well as in most standard relevant systems, from Woods's charge that relevant negation is no more a form of negation than a blunderbuss is a form of buss, to redirect Anderson and Belnap's old joke about material implication (1975: 5). The semantics of relevant negation are given by Routley's star rule, namely:

$$
\mathrm{V}(\sim \mathrm{A}, \mathrm{w})=\mathrm{T} \quad \text { iff } \quad \mathrm{V}\left(\mathrm{A}, \mathrm{w}^{*}\right)=\mathrm{F}
$$

in contrast to the rule for classical negation:

$$
\mathrm{V}(\sim \mathrm{A}, \mathrm{w})=\mathrm{T} \quad \text { iff } \quad \mathrm{V}(\mathrm{A}, \mathrm{w})=\mathrm{F}
$$

And the issue is that it seems counter-intuitive that $\sim \mathrm{A}$ should be true in a set-up w, iff A is false, not in that set-up, but in some other set up $\mathrm{w}^{*}{ }^{2}$ How can such a thing be anything like negation in English? Woods is not the first to object to it: the chorus of opposition has been sizeable and enduring, starting with Copeland (1979) and van Benthem (1979). What I want to suggest - though this is possibly the toughest audience in the world to which to sell the Routley star-is that, while relevant negation is not identical to ordinary language negation (if there is one such thing), it shares enough with it to count as a recognizable form of negation. My arguments are not original, most of them come from Routley et al. (1982).

Consider, first, the formal requirements commonly imposed on negation. They may be placed in the following four groups:

1 On reflection, I think that Woods is quite right not to flinch at my point about disjunction and conjunction. It is, indeed, quite plausible to suppose that dual operations will share a penumbral overlap. On the other hand, the point does indicate the weakness of the present condition, and suggest that there are stronger ones waiting to be discovered.

2 I follow the original terminology (Routley and Routley 1972; Routley and Meyer 1973) in speaking of 'set-ups' here, but terminology has fluctuated. Routley et al. (1982) and Mares (2004) use 'situations', Routley and Plumwood (1986) use ‘worlds'; Restall (1999) uses 'states'. 
1. Double negation (both ways)

$$
\mathrm{A} \rightarrow \sim \sim \mathrm{A} \quad \text { and } \quad \sim \sim \mathrm{A} \rightarrow \mathrm{A}
$$

2. Various inversion principles, notably:

modus tollens

and contraposition in all forms, notably:
$\mathrm{A} \rightarrow \mathrm{B}, \sim \mathrm{B} \mid-\neg \mathrm{A}$

$\mathrm{A} \rightarrow \mathrm{B} \rightarrow \sim \mathrm{B} \rightarrow \sim \mathrm{A}$

\section{De Morgan principles}

$$
\text { e.g. } \begin{aligned}
& \sim(\mathrm{A} \wedge \mathrm{B}) \rightarrow . \neg \mathrm{A} \vee \sim \mathrm{B} \\
& \sim(\mathrm{A} \vee \mathrm{B}) \rightarrow . \neg \mathrm{A} \wedge \sim \mathrm{B}
\end{aligned}
$$

and their converses.

\section{No contradiction and excluded middle}

$$
\text { (4a) } \sim(\mathrm{A} \wedge \sim \mathrm{A}) \quad \text { and } \quad(4 \mathrm{~b}) \quad \mathrm{A} \vee \sim \mathrm{A}
$$

Of these groups of principles, relevant negation satisfies all but the last.

Moreover, its rejection of group 4 is principled and pretty much inevitable, given the entire purpose of relevant logic, which (essentially) is to ensure that deductive reasoning can continue in the presence of inconsistency. The laws of no contradiction and excluded middle place consistency and completeness constraints on set-ups. Sets-ups may be regarded as sets of propositions, so that the classical negation rule, which validates (4a) and (4b) on all set-ups, can be written:

$$
\mathrm{V}(\sim \mathrm{A}, \mathrm{w})=\mathrm{T} \text { iff } \mathrm{A} \notin \mathrm{w}
$$

But this simply eliminates from consideration the sets of propositions which contain both $\mathrm{A}$ and $\sim \mathrm{A}$ and those which contain neither. But it was precisely the purpose of relevant logic to enable deductive reasoning to continue when such circumstances were in play. Accordingly, the classical rule has to go- or else we have to give up any hope of being able to use formal logic to argue sensibly about inconsistent or incomplete sets of propositions.

Of course, this does not in itself validate the star rule. So how do we get to star? One obvious requirement on the negation rule is that it preserve compositionality - that is, that the valuation of $\sim \mathrm{A}$ depend upon the valuation of $\mathrm{A}$. But, as we have just seen, the valuation of $\sim \mathrm{A}$ in $\mathrm{w}$ cannot depend upon the valuation of $\mathrm{A}$ in $\mathrm{w}$. So it must depend upon the valuation of $\mathrm{A}$ in some other set-up. So what is the set-up $\mathrm{w}^{*}$ ? In terms of sets of propositions, $\mathrm{w}^{*}$ is a set of propositions which does not contain any proposition explicitly denied in $\mathrm{w}$; that is, it is a set of propositions compatible with the propositions in $\mathrm{w}$.

Formally:

$$
\mathrm{V}(\sim \mathrm{A}, \mathrm{w})=\mathrm{T} \quad \text { iff } \mathrm{A} \in \mathrm{w}^{*}
$$


It is, in fact, the maximal set of such propositions. And it has some other nice properties, too. It is closed under deduction (there's a proof in Routley et al.: 133) and, given the De Morgan laws, it is unique (proof: ibid.: 134).

So $\sim \mathrm{A}$ is true in a set-up $\mathrm{w}$ iff $\mathrm{A}$ is false in the maximal set-up compatible with w. It looks almost commonsensical. But why can't w itself be the maximal set-up compatible with w? Because, if we acknowledge that set-ups may be inconsistent, as we have to if we are to get an adequate account of entailment free of the paradoxes of strict implication, then we have to allow for the possibility that w may not be compatible with itself! On the other hand, if we restrict our attention to set-ups which are consistent and complete, then relevant negation behaves just like classical, Boolean negation. So if you think Boolean negation is a bit 'not'-ish, then you ought to think that relevant negation is also a bit 'not'-ish, for there is a robust, philosophical sense in which relevant negation is an extension of, a generalization of, classical negation. Woods called for 'negationlikeness'-I think relevant negation has it in spades.

\section{AN ENDORSEMENT}

What I want to endorse strongly is Woods's conceptual-identity project. It is actually quite scandalous, when you come to think about it, how little effort philosophers put in to establishing identity conditions for the types of items that they typically regard as their stock-in-trade - concepts, propositions, and theories come immediately to mind. Given their importance in philosophy, one would expect their identity conditions to be the subject of tenacious debate. Yet little is said on the topic. I agree with Woods in rejecting Quine's 'grim epistemological Puritanism' which would require identity conditions to be specified before you could be said to know what you are talking about. But the converse does seem to me to hold: if you can specify an item's identity conditions then you have a pretty good handle on what you are talking about.

\section{A PROPOSAL}

Finally, the proposal I want to make concerns a possible way of pursuing the identity conditions project which may prove fruitful. Concepts nest together. They typically nest in theories (or other, looser, intellectual structures), where, like other nestlings, they not untypically have to adjust to the demands on nest space made by their companions. It may well be that a useful way to establish the identity conditions of a concept is to consider its role, vis-à-vis other concepts, in the intellectual structures in which it is employed. Such an approach, I think, will encourage our affection for relevant negation, for it surely plays a negationy role in relevant logic. 


\section{COMMENTARY}

\section{REFERENCES}

Anderson, A.R. and Belnap, N.D. (1975). Entailment: The Logic of Relevance and Necessity, Vol. I. Princeton: Princeton University Press.

Copeland, B.J. (1979). On When a Semantics is not a Semantics: Some Reasons for Disliking the RoutleyMeyer Semantics for Relevant Logic. Journal of Philosophical Logic 8, 399-413.

Mares, E.D. (2004). Relevant Logic. A Philosophical Interpretation. Cambridge: Cambridge University Press. Restall, G. (1999). 'Negation in Relevant Logics. (How I Stopped Worrying and Learned to Love the Routley Star'. In Gabbay, D. and Wansing, H. (eds). What is Negation (pp. 53-76). Dordrecht: Kluwer.

Routley, R. and Meyer, R.K. (1973). The Semantics of Entailment. In: Leblanc, H. (ed.). Truth, Syntax and Modality (pp. 199-243). Amsterdam: North Holland.

Routley, R., Meyer, R.K., Plumwood, V., and Brady, R.T. (1982). Relevant Logics and Their Rivals, Vol. I. Atascadero, CA.: Ridgeview.

Routley, R. and Plumwood, V. (1985). Negation and Contradiction. In: Caicedo, X., and Chuaqui, R. (eds). Proceedings of the Fifth Latin American Symposium on Mathematical Logic (pp. 201-231). Bogota: Sociedad Colombiana de Matemática.

Routley, R., and Routley, V. (1972). The Semantics of First Degree Entailment. Nous 6, 335-59.

van Benthem, Johann (1979). What is Dialectical Logic? Erkenntnis 14, 333-47. 


\title{
Reply to Nicholas Griffin
}

\section{JOHN WOODS}

\author{
University of British Columbia \\ and \\ King's College, London \\ john.woods@ubc.ca
}

I am extremely grateful to have Professor Griffin's endorsement and proposal, as well as the benefits of his criticisms, which if left standing would augur ill for my project. So I want in this short reply to make some effort to subdue the trouble they threaten.

The first criticism has to do with the very idea of semantic penumbra. Griffin is entirely right to notice that, as defined here, formal conjunctions can be in the semantic penumbra of disjunctions in English, and ditto for formal disjunctions and English conjunctions. Perhaps at first blush this is too much to bear, giving to semantic penumbra a latitude that dissipates the usefulness I claim for them. On thinking it over, however, it is the appearance of over-reach that dissipates, occasioned by the fact that conjunction and disjunction are one another's duals. So they are bound to exhibit some penumbrial overlap.

Where Griffin's worry was that I was too soft on semantic penumbra, he finds that I am too hard on star negation. Consider the negation sign " $~$ " under the star interpretation. I say that if the truth of $\ulcorner\sim \Phi\urcorner$ in a given set-up is guaranteed by the possible, not actual, falsity of $\Phi$ in that set-up, there is in English no sense of the expression "it is not the case that ..." in which if $\Phi$ is possibly but not actually false ${ }^{-}$it is not the case that $\left.\Phi\right\urcorner$. So (I said) there is in this sense of " $"$ " nothing recognizable as negation.

Against this, Griffin rightly points out that star negation appears to behave remarkably like real (as anyhow recognizable) negation in a variety of telling contexts. Double negation holds for star negation, as do modus tollens and the DeMorgan equivalences. Isn't star negation negation-like in these contexts? Doesn't this make negation recognizable here?

Consider a case. We have a formalization in which " $\sim$ " means "It is disbelieved by Sarah Palin that ...". The system is carefully rigged to have it come out that here too double negation, modus tollens and the DeMorgan equivalences all hold. In particular, 'It is disbelieved by Sarah Palin that $\Phi$ that it is disbelieved by Sarah Palin that $\Phi\urcorner$ is equivalent to $\Phi$. Is " " now recognizable as negation" Who would believe it?

Of course, the system I am alluding to here would have to go to considerable and ad hoc lengths to make Sarah-negation dance to these standard-seeming equivalences and rules. But is there a modern logician alive who thinks that ad hocery is off-limits in logic?

To my mind, something quite interesting falls out of the Sarah-negation example. It is beyond contention that nothing recognizable as negation is to be found in Sarahnegation. Yet, if you're clever enough, you can deploy Sarah-negation as the negations of those standard-seeming equivalences and rules. What does this tell us? It tells us that recognizability as negation and negation-likeness are not equivalent notions. It also tells us that negation-likeness is not sufficient for negation-recognizability.

A small last point on worlds. Griffin thinks that, owing to their susceptibility to inconsistency, we should not think of star worlds as possible worlds, and recommends instead a more neutral name such as "set-up". I don't mind. Nothing I have to say against

Zenker, F. (ed.). Argumentation: Cognition and Community. Proceedings on the $9^{\text {th }}$ International Conference of the Ontario Society for the Study of Argumentation (OSSA), May 18-21, 2011. Windsor, ON (CD ROM), pp. 1-2. 
star negation is predicated on the idea that some possible worlds are actually inconsistent. Let us note, however, that in the mainstream worlds semantics for intensional logics, there is not one word of instruction about what possible worlds are, beyond their purely formal characterization as elements of a non-empty set governed by a binary relation. On any such approach to modal logic, the invocation of worlds will tell us what "possible" means, but not what "possible world" means. So I am also happy with an occasional possibly impossible world - for consideration of the analysis, say, of contralogical subjunctive conditionals. 